me to think that this was the original form which the disease assumed on the fore part; it is, however, red, inflamed, and very tender. On detaching one of the scales from the front of the leg, the surface beneath exudes a serous discharge emitting a most offensive odour; indeed, the old man states that frequently the smell of his legs is so bad as to occasion him to vomit. From the inflamed appearance of the limbs, I felt rather disposed to employ emollient remedies, but on my suggesting these, the patient informed me that he had used them without benefit. I therefore ordered him an unguent, consisting of one-third of nitrate of mercury ointment and white precipitate ointment, rubbed in twice a day, after having first applied warm bran water to detach any loose scales.

Nov. 19th. Says the itching is not so violent, nor does the ointment occasion him any pain in its application. Repeat the ointment. Ordered two Plummer's pills every night, and s purgative dose of salts and senna every alternate morning.

22nd.-The re-formation of the scales does not proceed so rapidly as heretofore; for two days consecutively it appears to have ceased. Requested him to discontinue the ointment until his next visit.

Dec. 17th.- He has been persevering in the use of the ointment since the 29 th of November, and with marked benefit, the scales now forming being scarcely larger than those first seen on the calf of the leg.

30th.-Is so far better as to be able to put on his boots, and to walk the whole distance (a mile and a half) from his residence to the dispensary without pain. Sleeps well at night; has scarcely any itching; no appearance of scales on either leg, and says they are as sound as ever they were.

Iune 3rd.-He has found no return of the disease, and has resumed his occupation, which he had given up for upwards of four years.

Remarks.-The futility of applying emollient and soothing applications in scaly diseases of long standing, I have experienced on more than one occasion. The inflamed condition of the legs in this case evidently arose from the irritation kept up by the adhering scales, and the constant scratching of the patient himself. The disease was purely of a loca character, as was shown by its yielding so quickly to local remedies, the only medicines taken internally being some of an aperient nature, and the Plummer's pill as a slight alterative. The occupation of the patient, which led him to be constantly standing, had evidently been a predisposing cause of the disease; hence a subsidiary part of the treatment was keeping the legs always up. The combination of the nitrate of mercury ointment with the white precipitate $I$ consider a very valuable one; certainly each separately does not possess that power which by combination they mutually seem to exert. As a stimulant application, I prefer this combination to the iodide of mercury and sulphur ointment of M. Biett. Arsenical remedies might probably have been of service in this case, but as they did not appear to be called for, (the topical applications being so evidently beneficial,) I abstained from prescribing what I probably should have felt disposed to order, had the patient been younger.

Pityriasis simplex.-D. $\boldsymbol{J}$ - aged two years, was brought to the dispensary Jan. 14th, 1846. The mother describes the complaint as originating, at two montlis old, "in pimples of small size, which came out all over the body, and when scratched appeared to become white, like nettle-rash," (an unusual appearance until the period of dentition.) The skin is now covered from head to foot with an eruption of brightred, superficial patches, most vivid on the face, chest, and back, as far as the shoulders; the insides of the arms and thighs, and the flexures of the joints, are similarly affected. Some slight roughness is observable on passing the hand over the patches, but not amounting to the branny desquamation sometimes observed in these cases. The child is lively, but excessively irritable, constantly scratching himself with his hands, and contorting his body with a view to relief from the violent itching. The bowels are usually regular; but the motions are dark-coloured and ofrensive. Has been allowed to take anything in the shape of food, meat, cabbage, turnip, and whatever else has been at the family table. Ordered, mercury with chalk, three grains; powdered rhubarb, four grains. To be bathed night and morning in warm bran infusion, and to live exclusively on milk diet.

On the 17 th and $24 \mathrm{th}$, the powders were repeated, and, at the latter date, the motions had assumed a healthier appearance. He was ordered iodide of potassium, one grain, three times a day, in a teaspoonful of water. The eruption on the face and back is not so red; but the itching still continues 27 th.-The itching not being allayed by the bran watera, lotion of hydrocyanic acid, fifteen grains to six onnces of fluid, was ordered. The eruption is decreasing.

Fel. 11th.-Some of the patches on the bowels and face have become so excoriated by the continual scratching, that I ordered the oxide of zinc ointment to be applied to them, and the other remedies to be continued.

28th.-The itching still continues in the face, back, and bowels, though the patches elsewhere are disappearing. Ordered diluted nitrate of mercury ointment to be rubbed on the face and shoulders night and morning, and to continue the powders and mixture.

On the 7th of March, the eruption on the face was declining, a yellowish stain appearing on the back.

On the 18th, I ordered sublimed sulphur, ten grains, to be taken in sugar every morning, and to remit the mixture and powders.

28th. - An evident improvement. The child continued getting better from this period up to his being discharged cured on the 1 st of May, the principal remedies being mercury with chalk and rhubarb, to correct the secretions, and where the itching was violent, the use of subborate of soda lotion. The strictest attention to diet was enjoined throughout the whole progress of the treatment, and $I$ have reason to believe was actually observed.

Remarlis.-Cases of pityriasis simplex are very common among infants and children during the period of dentition. In this case, the child had cut all his milk teeth, therefore $I$ was disposed to attribute the obstinacy of the complaint to a disordered condition of the primæ vix. The secretions were vitiated generally; the tongue was coated, and the mucous membrane of the nose was in an unhealthy state. The mercury with chalk and rhubarb is a very valuable alterative for children, and, combined with small doses of ipecacuanha, it is particularly useful in skin diseases arising from an improper state of the digestive functions. In a case of pityriasis discharged recently, the child was one year and a half old, of weakly constitution, disposed to struma. I found here considerable benefit from the mercury with chalk, rhubarb, and one-sixth of a grain of quinine in each powder; and the itching became speedily allayed under the use of the sulphuret of potassium lotion. The patient had been under treatment since the 21st of February last, his symptoms being precisely similar to those of the case just related. Greasy applications I have seldom found of much service. When abrasion of the skin occurs from scratching, zinc ointment may be used with advantage; but as far as my experience goes, I believe local applications, whether in the shape of ointments or lotions, are seldom productive of permanent benefit. Disorders of the skin evidently dependent on constitutional derangement can only be relieved by internal remedies.

ON

\section{CARNIFICATION OF THE LUNGS IN CHILDREN.}

By G. A. Rees, M.D., London.

Carnirication of the lungs occurring in the young subject unconnected with effusion into the pleure, was firsi noticed in a letter sent by me to the Medicul Gasctte, and published in January, 1839. Since that period it has been described by several French writers, first by MII. Barthez and Iilliet in their treatise, "Des Maladies des Enfants," published in 1843 , and more recently by MIII. Bailly and Legendre, who, in the Archives Générales de Mélecine for 1845 , have instrted two consecutive papers on the same subject. Dr. West, in a paper on "Pneumonia in Children," published in the British and Foreign Medical Peview, has also alluded to it, quoting from MIX. Barthez and Rilliet, without mentioning any countryman of his own as having first described this pathological condition. I thought, therefore, that the following remarks would not prove uninteresting to the English medical reader.

To elucidate the subsequent observations, a slight sketch of a few cases is indispensable.

CASE 1.-Mrs. B-'s infant appeared still-born. After a lapse of ten or twelve minutes, the usual restoratives having been cmployed, the first symptom of animation was perceptible. This consisted of a sudden inspiratory effort: the chest was uncovered at the time, and it was observed that the lower ribs at the same moment, instead of moving upwards and outwards, as in ordinary respiration, were drawn, or rather forced inwards, towards the mesial line, giving a peculiar constricted appearance, for the instant, to the base of the thorax. After a short interval, another inspiration succeeded, fuller and freer than the first, the abnormal movement of the ribs being 
less visible. After a third and fourth inspiration the child cried, the lung became fully expanded, and the ribs assumed their proper movement.

This is a simple example of recovery from asphyxia in the newly-born infant, the point of interest to which the writer would direct attention being the altered movement of the ribs, which he has always observed in similar cases to continue until healthy respiration is fully established.

CASE 2.-Eliza R_, aged two months, living in Orangestreet, Bethnal-green, was brought to the General Dispensary for Children with symptoms of the last stage of pneumonia; great dyspnœa, with lividity of countenance, cold extremities, and other evidences of collapse being present. The state of the infant forbade any careful examination, but I detected small crepitation over the lower lobes of the lungs; there was also the unnatural movement of the ribs in respiration alluded to in the first case, the ribs being pressed in considerably at the moment of inspiration.

The mother stated that the infant cried very feebly when first born, had been very delicate and weakly since birth, and had always suffered from cough and shortness of breath, accompanied by drawing-in of the chest. The infant died shortly after I had seen it.

Post-mortem examination, forty-eight hours after death.-Body diminutive, much emaciated; sternum and costal cartilages very prominent, giving the chest a spherical appearance* on its front surface. On opening the thorax, the lungs appear shrunk, imperfectly filling the cavity. These organs are of a bright florid-red colour on their upper surfaces. On the superior lobe of the left lung is a large sub-pleural emphysema, of the size of a pigeon's egg. There is also interlobular emphysema apparent over the upper lobes of both lungs, the emphysematous points looking somewhat like minute glass beads scattered over the lungs. The lower lobes of both lungs are of a dark-purple colour, and almost entirely solid, some portions having the appearance of lung carnified from compression, but without the same degree of flaccidity. On tracing the bronchi into the lower lobe of the left lung, some dilatation of the primary divisions was apparent, but no obstruction nor obliteration of the lesser tubes could be detected. With the exception of some enlargement of the mesenteric glands, the abdominal viscera were healthy. The head was not examined.

CASE 3.- James $\mathrm{K}-$, aged three years, residing in Grocers'-hall Court, when first seen by me, was in a dying state; suffering from great difficulty of breathing, quick and irregular pulse, livid countenance, swollen and cold extremities, and other signs of a moribund condition. On examination, the chest was found much deformed, the ribs bending in near the junction with their cartilages, as in ordinary strumous deformity of the chest. There was also the altered movement of the ribs, but less considerable than in the infant, Case 2. The abdomen was much enlarged: there was evidently ascites; and on slight pressure, a very greatly-enlarged spleen could be felt, occupying the left half of the cavity.

The mother stated that the child had been ill eight months ; that previous to that time he had been healthy, able to walk about, and that no deformity of the chest was apparent; that his illness commenced with a violent cough; that his breath had been short since then, and the chest had become more and more contracted : among other symptoms she mentioned epistaxis, to which he had been liable at intervals to a considerable extent, the blood running from the nostril in a stream. It is about ten months since he moved from a more healthy situation to the close neighbourhood of Grocers'hall Cour't.

Post-mortem examination, twelve hours after death.-Rickety deformity of the chest; emaciation; abdomen much enlarged; on opening the thorax, the pericardium, containing a greatly enlarged heart, the most prominent object, owing to the hypertrophy of which organ, and the narrowing of the chest, only a small portion of lung was visible; the veins of the neck, the renæ jugulares, and venæ innominatæ, turgid with blood; the right cavities of the heart also much distended, these cavities being greatly dilated the valves of the heart healthy; the lungs shrunk to half their size, of a purple colour, with here and there ecchymosed patches of a brighter hue; these organs, to the feel, flaccid, impertectly crepitating, some portions quite solid, and accurately resembling lung

* Great prominence of the front surface of the chest is often a marked symptom of disease of the lower lobes of the lungs in infants, and in those cases the prominence gives a very peculiar rounded form to the chest. carnified by the compression of effusion into the pleura. Abdomen : Ascites; the liver much enlarged, of a dark colour; on incision, the venæe cavæ hepaticæ found gorged with blood; the gall-bladder full; the spleen very much augmented in volume, being half the size of the liver, the enlargement apparently dependent upon venous congestion; the pancreas healthy; the mesenteric glands enlarged; the in. testines healthy, with the exception of enlargement of Peyer's glands; kidneys much congested; spots of ecchymosis apparent under the fibrous tissue; the calyces and infundibula occupied by a substance of a purple colour, apparently firmly coagulated blood; head not examined.

CASE 4.-Elizabeth $\mathrm{L}$ - living in a back room, ground. floor, Long-alley, aged ten months, brought to the dispensary for shortness of breath and cough, presenting the same set of symptoms as in Case 2, without the same degree of collapse, the cough, of a peculiar character, being short, and at times reiterated as in pertussis ; the dyspnca considerable, and the altered movement of the ribs very remarkable. On examination of the chest, the ear detects loose bronchial râle here and there, and over the lower lobes of the left lung small crepitation. The abdomen tumid; bowels confined; tongue coated.

The mother's account is as follows: The infant was a seven months' child; apparently still-born, but recovered gradually. It has been subject since birth to shortness of breath; the mother always observed the altered movement of the ribs, and when she took it to St. Bartholomew's Hospital, pointed out the circumstance. It came to live at Long-alley six months since, and from that period has gradually declined. About six weeks since, it suddenly became feverish and more oppressed in its breathing, and the cough then first com menced, being peculiarly harsh, and "causing a blue vein to rise up in the neck."

The treatment in this case, which was very simple, seemed at first to relieve, and the patient revived for a few days; but the improvement was of short duration-the dyspnoea and cough prevented the infant's rest, and it sank gradually from exhaustion, after it had been attended about three weeks.

Post-mortem examination, twelve hours after death.-The body emaciated; abdomen tumid; lower extremities rickety. On opening the chest, the lungs somewhat small, and a large portion of those organs solidified, the solid portions being of a dark-purple colour, and soft, flaccid feel; in fact, exactly similar to carnified lung, this carnification extending over a considerable part of the upper and lower lobes of both lungs, especially along the thin marginal edge of the lobes and the middle lobe of the right lung. On inserting a blow-pipe into the right bronchus, and inflating the corresponding lung through it, the organ becomes pervious to air throughont nearly the whole of its extent, a great portion, previously solid, admitting the air, losing its purple tinge, and assuming its healthy appearance. The pericardium healthy. The heart of average size; small digitations on tricuspid valves; the remaining valves healthy. Abdomen : The liver healthy, but large; the venæ cavæ hepaticæ turgid; the gall-bladder full pancreas and spleen natural; the stomach and intestines much distended with flatus; mesenteric glands hypertrophied; the stomach and intestines perfectly healthy. Head: Bones widely separated, only very partially ossified; the sinuses full; on removing the calvarium some effusion observable beneath arachnoid covering hemispheres; brain soft, numerous bloody points on centrum ovale; the remainder of the organ healtby.

Remar7ss.-From these and many similar cases the writer deduces the following propositions:-

1. In the infant, apparently still-born but slowly recovering from the state of asphyxia, the first symptom of animation consists in a sudden and abrupt contraction of the diaphragm constituting the primary effort at inspiration.

2. The expansion of the lung at that moment is not in relation with the descent of the muscle, nor is it so until respiration is fully established.

3 . Owing to this, a very singular and interesting circumstance will be noticed, if the thorax of the infant be carefully observed; for, during the inspiratory effort, the ribs move in wards towards the mesial line of the trunk, instead of out wards, as in ordinary respiration, diminishing instead of increasing the transverse diameter of the chest. This is easily accounted for; were it otherwise, the descent of the diaphragn without corresponding expansion of the lung would cause a vacuum in the chest; external atmospheric pressure prevents this by inducing the abnormal movement of the ribs just de. scribed. 
4. Usually after a few seconds the infant cries; this is followed by a deeper inspiration; the lung becomes more fully expanded; the altered movement becomes less and less apparent, and complete respiration is soon established. But in other instances such is not the case; from some cause, the lungs remain only partially expanded, the child respires in an imperfect manner, and the altered movement of the ribs remains permanent and irremediable.

5. But as this is owing to imperfect expansion of the lung, any cause occurring after birth, and while the parietes of the chest are yet yielding, which prevents the lungs being filled with air, would, it might be supposed, induce the same movement of the ribs, whether this cause exert its influence upon the primary air-tubes or on the lungs themselves. CEdema of the glottis, the false membrane of croup, while yet unaccompanied with effusion into the pulmonary tissues, and lastly, lesion of the lungs, rendering those organs impermeable to air, without augmenting their volume, would be supposed likely to originate, and, I believe, will be found to produce, this phenomenon.

6. Nor will this symptom prove of small value if looked for and attended to. In laryngitis and croup it will inform to a degree as to the state of the lungs, and may assist the surgeon in deciding as to the propriety of tracheotomy being performed. If the altered movement be considerable, the lungs are yet free, and the incision may afford relief, but if, with strongly marked tracheal or laryngeal breathing, the ribs are immovable, effusion has taken place into the pulmonary tissue, (augmenting the volume of those organs while rendering them inaccessible to air, and tracheotomy will be in vain.

7. The most common cause of this altered movement is carnification of the lung unconnected with any pleuritic effusion, in which, while the portion of the organ affected is rendered solid, and no longer permits the air to permeate its interior, it is at the same time diminished in volume, and therefore occupies a less space in the thoracic cavity.

8. This change of structure in the lung produces many and various changes in the appearance and constitution of the child.

(a.) In infants who have only partially respired, after a few weeks or months it becomes associated with laryngismus stridulus, and the case often terminates suddenly in one of the attacks of dyspncea. The imperfect expansion of the lung renders necessary an exact equilibrium between the inspiratory and expiratory effort, and any sudden exertion destroying such balance produces spasmodic closure of the glottis.

(b.) Enlargement of the abdomen is another effect of carnification. From the altered movement of the ribs the abdominal muscles lose their fixed point, their point d'appui, and fail to exert due compression on the viscera they enclose. Hence, tumid abdomen and constipation of the bowels; and this led Dr. Snow (who recognised the altered movement after I had described it) to attribute it to an enlargement of the abdomen, mistaking, as I believe, the effect for the cause.

(c.) Venous congestion of the abdominal viscera, partly dependent upon want of proper compression from the abdominal muscles, but more particularly owing to the embarrassment of the pulmonary circulation, is sure to succeed to a greater or less extent. In Case 3, the liver was found enlarged, with gorged venæe cavæ hepatica, and the spleen was much hypertrophied; there was also observed, congestion of the mesenteric and intestinal glands, and of the kidneys.

(d.) Congestion of the cerebral vessels is a frequent concomitant morbid appearance, rendering the infant during life subject to meningitis or effusion. In the case of $J . K-$ this congestion was prevented by periodic and severe epistaxis.

(e.) The increased difficulty in the general and pulmonary circulation will have an effect on the central organ of that system. The heart becomes hypertrophied, and adds to the general derangement, the hypertrophy being sometimes much more observable on the right side; the right ventricle I have seen so much dilated as to alter the shape, giving the idea of a double-apexed heart.

(f.) Deformity of the chest, at a more or less remote period, results as a means of adapting containing to contained parts. If there be a strumous diathesis present, we have, as in Case 3 , strumous or rickety deformity of the chest, the bony structure of the ribs themselves yielding near the junction with their cartilages; and this explains to my mind a difference which before I could not account for-namely, why, in one instance, with considerable rickety deformity of the extremities, there is a fully expanded and well-formed chest, while in another, with the limbs straight, but weakly, the altered shape of the chest is so considerable; it is becanse, in the latter case, the lungs have previously become shrunken. Oring to a vitiated atmosphere or other depressing cause, carnification of the lung has taken place to a greater or less extent, and the walls of the chest are forced inwards, to adapt themselves to the shrivelled state of the respiratory organs. This explains the statement of M. Edwards, - a statement confirmed by AIr. Ward before the Committee of the House of Commons, - that in dark and illventilated abodes it is that children are most frequently observed deformed. In my own practice I have found the same hold true, and have now children under my care, who are born of apparently healthy and extremely well-formed parents, suffering under very great rickety deformity of the chest brought on, I believe, solely by the unhealthy situation in which they were brought up.

But where no strumous diathesis is present, where the bones are of firmer consistence, and the cartilages healthy, the contraction is of a different kind, and takes place at the point of union between the ribs and their cartilages; here a depression ensues, and the chest becomes channelled on either side-a change of form I have never observed under any other circumstances.

Having enumerated some of the symptoms and consequences of this form of carnification in children, the question naturally suggests itself-what is the nature of so singular a pathological condition? to which no satisfactory reply can, I believe, as yet be given.

In considering this part of the subject, it is necessary to bear in mind that there are two sets of cases to be explained there are those where the lung has never been expanded from birth, in which the unexpanded portion of that organ resembles very closely carnified lung; and there are those instances, of which we have an example in Case 3 , where the change is evidently a post-natum occurrence, and where the affected portions so exactly similate carnified lung, that I believe it would be impossible to distinguish, from mere inspection, between them.

My idea, when first I noticed this change of structure, was, that it depended upon a modification of inflammation running a slower course, that it was chronic pneumonia; and, singularly enough, Messrs. Barthez and Rilliet, in their treatise,written, I suppose, in ignorance of my prior paper,-almost quote my words. They state-_"Cette alteration assez frequente n'a pas été decrite par les auteurs," and add, "ou serait porté a regarder la carnification comme une sorte de termination de la pneumonie, ou comme une pneumonie chronique."

Messrs. Bailly and Legendre, in their paper in the "Archives Générales de Médecine," have carefully distinguished between the two sets of cases mentioned above, and have changed the name carnification for l'état foetal, or fotal state, as I think injudiciously, and without sufficient reason; their chief inducement for doing so they allege to be, the indefinite use of the terms carnification and hepatization. In our own country, I believe, carnification, as distinguished from hepatization, is well understood by any person at all conversant with the matter; but, moreover, of this denomination, they recognise two modifications-namely, the simple fotal state, and the fotal state with congestion ; and, unfortunately for the term they have selected, it is the latter modification that is found in those infants whose lungs have never been expanded. If any change had been necessary, the term atalectasis pulmonum-first proposed by Professor Joerg, of Berlin-would have been, in my opinion, the more desirable substitute.

Messrs. Bailly and Legendre's description of the points of difference between this change and hepatized lung is very correct. In the course of this paper, the chief characteristics of carnification have been mentioned, and therefore it is unnecessary to give a summary here; but there is one worthy of especial remark-namely, the effect of inflation in restoring the carnified lung to its healthy appearance. I believe this to be most characteristic of carnification; and although M. Bouchut, in his treatise on the diseases of infants, states that the same effect may be produced in hepatization of the lung, I have no hesitation in stating, from my own experience, that he is incorrect in his opinion.

Messrs. Bailly and Legendre, after an enumeration of the symptoms, in which no mention is made of the altered movement of the ribs, give as their opinion, that the cause is a deficiency in the respiratory power, "un ralentissement des forces respiratoires." I totally disagree with them on this point. The altered movement of the ribs in respiration-which $I$ feel persuaded is the most characteristic symptom in such cases-could only originate from the respiratory efforts being excessive, compared with the expansion of the lungs; but, moreover, if, on this point, my opinion be erroneous, the emphysematous state of the upper lobes of the lungs, in Case 2. 
would afford to my mind ample evidence of their mistake. Nothing but continual and powerful respiratory efforts could induce such appearances as were present in those lungs.

There seems at present considerabledifficulty in ascertaining the real cause of these singular pathological changes. I cannot believe them, as I at first supposed, to be the result of inflammation, for there are no evidences, but atrophy, of that state having pre-existed; nor do I think the cases are benefited by antiphlogistic treatment; on the contrary, nourishment carefully administered, with tonic medicines, change of air, and encouraging, by warm clothing, the action of the skin, form the plan that has proved most successful in these patients.

The one point on which I feel decided is, that the carnification occurring after birth is in some way connected with the respiration of impure air, though it is not easy to deter mine how these organs are led by occlusion of the air-cells to become impermeable to the vitiated atmosphere around them.

Artillery-place, Finsbury-square, April, 1846.

AN ACCOUNT OF A CASE OF

\section{HYPERTROPHIED SCROTUM AND PENIS;}

\section{EXTIRPATION BY OPERATION, AND RECOVERT.}

\section{BY FRED. HARINGTON BRETT, Esq, F.R.C.S.,}

SURGEON TO THE WESTERN OPHTHALMIC INSTYTUTION, DORSET-STREET, POLTMAN-SQUARE; IATE SURGEON TO THE GOVERNOR-GENERAL'S BODY-GUARD, AND EYE INFIRMARY, BENGAL.

JoHN $\mathrm{S}-$ - locksmith, aged forty. His disease originated about four years ago. The skin of the scrotum is in parts warty, having fissures in others, and ulcers, leading to short sinuses, from which serous pus can be squeezed. He is naturally phymosed to such an extent as that the prepuce appeared like a second glans penis, of about 2.5 in diameter. Twelve years ago he had stricture; four years since, urine extravasated, and the scrotum commenced enlarging after urinary abscesses. For twelve months past the penis had enlarged, and was still increasing in size.

Nov.14th, 1845.-Two inches of the prepuce and the diseased growth were cut off, and catheter No. 7 was introduced.

18th.-Incisions were made into the scrotum by laying open sinuses.

28th.-Ulcers of the incisions discharge pus freely, and pressure was made laterally, by compression with bandaging and strapping; cedema prevented by raising the tumour.

Dec. 22nd.-Cicatrix of prepuce again growing, so as to obliterate the orifice of the urethra.

Jan. 22nd, 1846.-Although the tumour occasionally diminished, yet there was no probability of recovery from the disease. Pressure had received a fair trial, both in the country and in the metropolis. Health suffering from long confinement in hospital, and from the drain kept up from the sinuses. Urethra now quite sound, and no fistulous communication with the sinuses below. Returned to the country, his case being generally considered incurable, or an operation dangerous, if not unjustifiable.

March 1st.-Came to town much restored in health. It was deemed expedient, in consultation, to extirpate the disease.

Operation.-One hour previously seventy drops of laudanum were administered, in order to produce a sedative effect, and to obviate, in some measure, the shock of the operation on the system. The patient being placed on a table, as for the operation of lithotomy, the tumour (fig. 1) was gently raised on the abdomen. Two superficial incisions were commenced, in the form of an isosceles triangle, in the perinæum, the apex pointing backwards, extending through the integuments. The tumour was then turned down, and by its own weight and pressure suppressed hremorrhage. A long and deep incision was then made, commencing from the external abdominal ring, and terminating at the inferior part of the right testis. The cord was exposed and isolated, and with the testicle carefully dissected out, and reflected on the abdomen. The same was effected on the opposite side, the operator being most scientifically assisted by Messrs. Lane, Pettigrew, Spitta, and others. A large lateral flap was then immediately formed on each side of the tumour, joining the corresponding sides of the isosceles triangle in the perinaum, by a rapid thrust of the catlin. Assistants were in readiness to place their hands on the bleeding surfaces, and suppress hæmorrhage; the superior extremities of these last incisions were joined by one carried under the root of the penis, which organ being drawn up, the

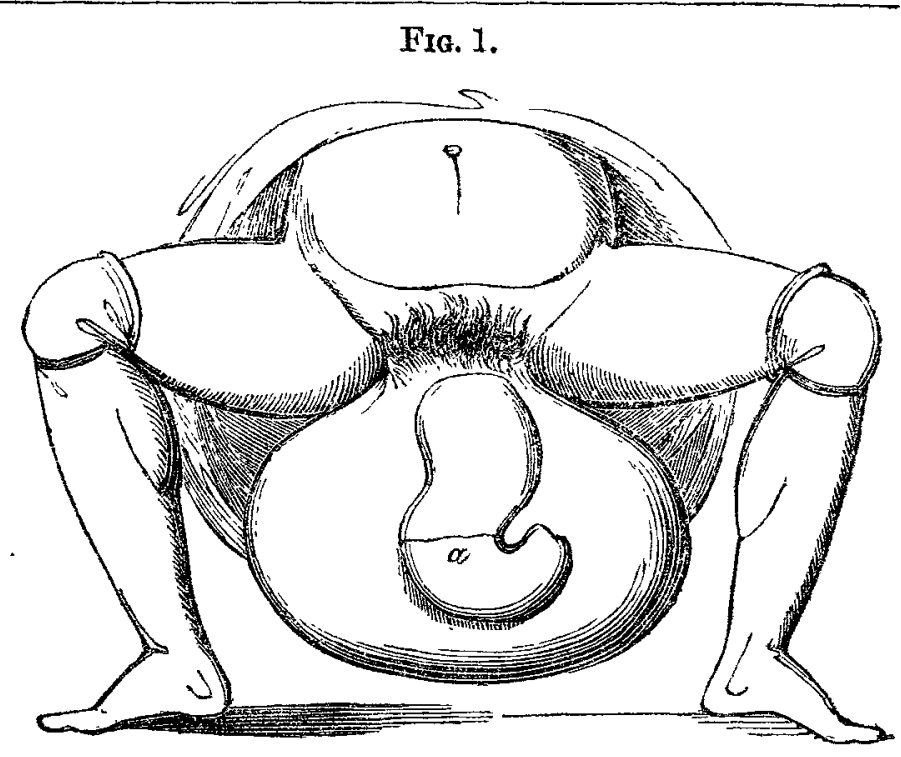

Vertical circumference of scrotum, 26 inches ; lateral ditto, 24 inches; penis and scrotum, 7 inches. a About level of glans.

tumour was, with all due expedition, dissected off from the root of the penis and perinaum. Pressure being still continued, a circular incision of the integuments of the penis above, about an inch and a half in advance of the pubes, was made, dissecting up just so much of the surviving healthy integuments. A rather bold longitudinal incision was now carried to the dorsum penis, taking care to avoid wounding the elongated prepuce, (that part which Nature arbitrarily adapts to her purposes, whether of mucous membrane or skin,) and having cleared away this morbid semi-cartilaginous mass, the prepuce was reflected (as exhibited in the diagrams, figs. 2 and 3) so as to meet the portion of healthy integument at the pubic extremity, there to be united by suture.

Fig. 2.

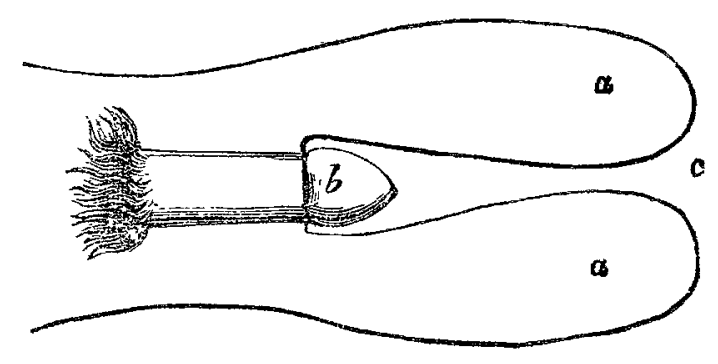

A Vertical Section.

$a$, Prolonged mucous membrane, or prepuce. $b$, Glans. $c$, Orifice whence the urine escaped.

FIG. 3.

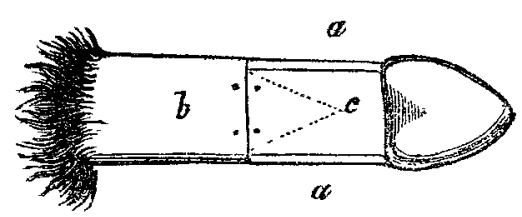

Perpendicular View of the same Mucous Membrake. $a, a$, Refiected back on the penis, and meeting the healthy portion of skin, $b$, saved from the root. $c$, Point of suture.

The operation being thus terminated in about ten minutes from its commencement, the divided surfaces readily admitted of adaptation, as represented in fig. 4. Interrupted suture, compresses, and a $T$ bandage, terminated oux efforts to relieve the patient from a disease which was a burthen to him. A quart of blood may be stated as the maximum quantity lost. which was chiefly venous. A gum-elastic catheter was introduced into the bladder, secured by a stopper, so that the urine might be carefully drawn off, and none fall on the wounds.

Details of thecase after operation.-Seven P.M. : Six hours aftes the operation. Has vomited; pulse 108, evidently showin the effects of the loss of blood; considerable malaise anc depression, though no pain. Nevertheless, the prognosis is b no means unfavourable. Has dosed at intervals. A smal quantity of brandy-and-water was administered. This $r$ mained for half an hour on the stomach, and was then rejected 